\title{
KARAKTERISASI KOROSI BAJA PADUAN RENDAH DI LINGKUNGAN 60\% LiBr PADA SUHU DIDIH CORROSION CHARACTERIZATION OF LOW-ALLOY STEEL UNDER 60\% LIBr ENVIRONMENT AT BOILING TERMPERATURE
}

\author{
Harsisto \\ Pusat Penelitian Metalurgi - LIPI \\ Kawasan PUSPIPTEK Gedung 470 Serpong, Tangerang 15314 \\ e-mail: harsistosardjuri@yahoo.com
}

Tanggal masuk naskah : 18/07/2014; Tanggal revisi: 19/09/2014 ; Tanggal persetujuan cetak : 08/10/2014

\begin{abstract}
Abstrak
Penelitian karakterisasi baja paduan rendah berbasis krom dan mangan ini dilakukan karena adanya masalah korosi merata dan korosi batas air pada baja karbon rendah.

Berdasar fakta di lapangan,mesin pendingin tersebut dilakukan "on-Off" setiap hari sehingga ada pengaruh udara luar dan turunnya suhu hingga suhu ruangan. Berdasarkan penelitian dan pembahasan tentang karakteristik 5 jenis baja paduan rendah dengan kandungan $0,5 \%$ berat unsur mangan

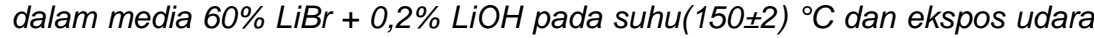
atmosfer selama 50 jam dan 110 jam, hasilnya menunjukkan bahwa laju korosi masih tergantung pada kadar kandungan unsur krom. Pada penambahan unsur krom dalam baja paduan rendah yang diekspos dalam larutan uji, tidak menunjukkan adanya konsistensi harga potensial korosi alaminya, tetapi secara umum semua benda uji berada dalam keadaan terkorosi.
\end{abstract}

Kata Kunci : mesin pendingin ruangan, baja paduan rendah, korosi, $\mathrm{LiBr}$, $\mathrm{LiOH}$, suhu didih dan suhu ruangan.

\begin{abstract}
Research-based characterization of low alloy steel chrome and manganese is done because of the problem of corrosion and corrosion limit water evenly on low carbon steel. Based on the findings, the engine coolant is switched on-and off every day so there was influence of outside air and the decrease of the temperature to room temperature. Based on the research and discussion of the characteristics of the five types low alloy steel containing 0.5 wt $\%$ manganese in the medium $60 \% \mathrm{LiBr}+0.2 \% \mathrm{LiOH}$ at a temperature of $(150 \pm 2){ }^{\circ} \mathrm{C}$ and exposure to atmospheric air for 50 hours and 110 hours, it showed that the corrosion rate is dependent on the level of content of the chromium. In the addition of the chromium in low alloy steels exposed in the test solution, there is no consistency in the natural corrosion potential value, but in general all test objects were in a corroded state.
\end{abstract}

Keywords : air conditioner, low alloy steel, corrosion, $\mathrm{LiBr}, \mathrm{LiOH}$, the boiling temperature and the room temperature.

\section{PENDAHULUAN}

Mengacu Majalah Tempo, "Penyejuk Udara tanpa Listrik", edisi 24-30 Maret 2014, IImu dan Teknologi, Halaman 110-
111 , sistem pendingin ruangan besar skala gedung pencakar langit akan lebih efisien dan efektif bilamana menggunakan mesin pendingin bermedia larutan pekat $\mathrm{LiBr}$. 
Larutan pekat $\mathrm{LiBr}$ dalam mesin pendingin berfungsi sebagai absorben atau media penyerap uap air untuk menurunkan tekanan sistem hingga di bawah $6,5 \mathrm{mmHg}$. Permasalahan yang muncul dengan menggunakan larutan pekat $\mathrm{LiBr}$ pada suhu didih, sangat korosif terhadap material kontainer atau reservoir logam baja.

Guna mencapai usia pakai mesin pendingin berkonstruksi baja yang ditargetkan lebih dari 20 tahun, maka dicari berbagai upaya pengendalian korosi yang terjadi.

Berdasarkan pengamatan di lapangan, korosi yang terjadi di permukaan logam baja karbon biasa adalah jenis korosi merata dan korosi batas air. Korosi merata didominasi terjadi di bagian logam baja yang terekspos larutan pekat LiBr. Korosi batas air yang parah terjadi di bagian permukaan logam baja yang terekspos larutan pekat $\mathrm{LiBr}$ dan sebagian terekspos uap air.
Pada prakteknya di lapangan, dengan adanya masalah korosi merata dan korosi batas air di atas, telah digunakan inhibitor $\mathrm{LiOH}$ dan $\mathrm{Li}_{2} \mathrm{CrO}_{4}$. Penggunaan inhibitor $\mathrm{LiOH}$ dimaksudkan untuk meningkatkan harga $\mathrm{pH}$ larutan pekat $\mathrm{LiBr}$ agar tercapai kondisi pasif dalam diagram $\mathrm{pH}$ - potensial atau diagram Pourbaix. hingga $9,02 \%$ berat dan penambahan unsur mangan sekitar $0,5 \%$ berat.

Penambahan inhibitor $\mathrm{Li}_{2} \mathrm{CrO}_{4}$ dimaksudkan untuk meningkatkan dan menstabilkan sistem logam baja dalam larutan pekat $\mathrm{LiBr}$ pada suhu didihnya dalam kondisi pasif.Fakta di lapangan dengan penambahan inhibitor $\mathrm{Li}_{2} \mathrm{CrO}_{4}$ telah terjadi korosi lokal tipe sumuran.Terjadinya korosi lokal tipe sumuran ini sangat membahayakan karena dengan pengamatan visual di bagian permukaan yang tidak begitu terkorosi tetapi di bagian dalam material logam bisa terkorosi berat hingga sangat keropos.

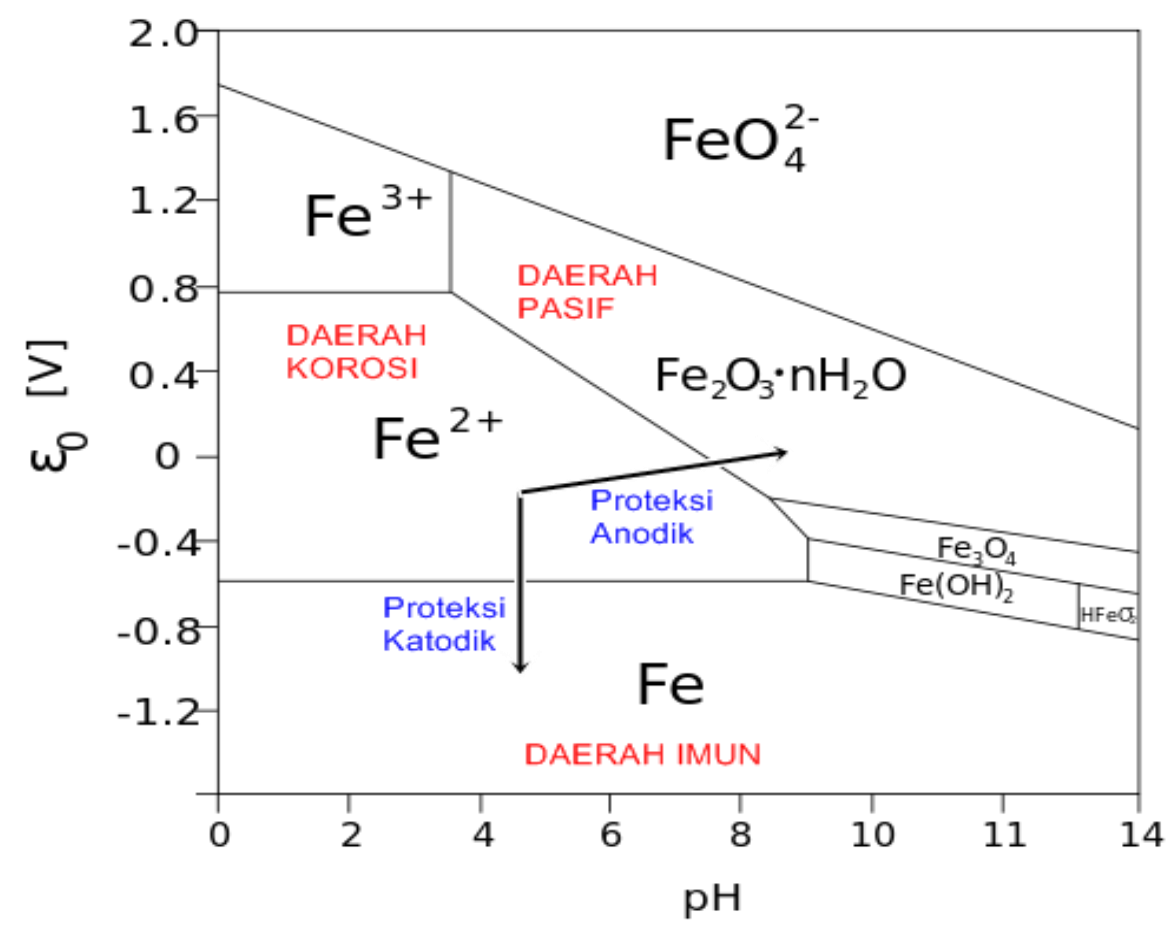

Gambar 1 : Diagram Pourbaix $\mathrm{Fe}-\mathrm{H}_{2} \mathrm{O}$ pada suhu ruang

Pada penelitian di sini, merupakan lanjutan dari penelitian dalam lingkungan korosif yang sama dengan material logam baja paduan tinggi dengan maksud menemukan material logam yang murah dan efektif tahan korosi untuk mesin pendingin ruangan. Kegiatan yang utama adalah meteliti pengaruh unsur-unsur penambah dalam baja paduan rendah terhadap laju korosi serta karakter hubungan $\mathrm{pH}$ dengan potensial korosi alami, yang didasarkan pada diagram Pourbaix. Unsur-unsur 
penambah dalam baja paduan rendah yang digunakan penelitian adalah variabel penambahan unsur krom dari $0 \%$

2. BAHAN DAN METODA

2.1. Benda Uji dan Larutan Uji
Benda uji yang digunakan adalah pelat baja paduan rendah yang diperoleh dan dibuat khusus dari pabrik baja PT. Kawasaki Steel co. Itd Jepang. Kompososi kimia benda uji tersebut dapat dipelajari pada Tabel 1. Dimensi pelat benda uji dari pabrik baja adalah tebal $5 \mathrm{~mm}$, lebar $80 \mathrm{~mm}$ dan panjang $120 \mathrm{~mm}$.

\section{A. Benda Uji}

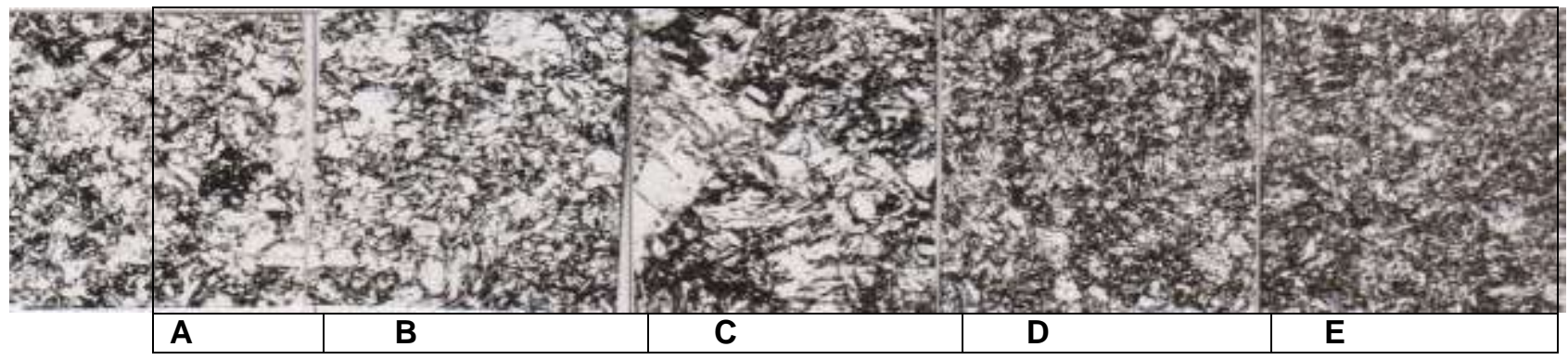

Gambar 2 : Foto mikrostruktur benda uji

Tabel 1 Komposisi kimia baja paduan rendah

\begin{tabular}{cccccccc} 
Jenis & \multicolumn{7}{c}{ Komposisi Kimia, \% berat } \\
\cline { 2 - 8 } Baja & $\mathrm{Cr}$ & $\mathrm{Mn}$ & $\mathrm{Al}$ & $\mathrm{C}$ & $\mathrm{P}$ & $\mathrm{S}$ & $\mathrm{N}$ \\
\hline $\mathrm{A}$ & 0 & 0,25 & 0,05 & 0,15 & 0,014 & 0,010 & 0,002 \\
\hline $\mathrm{B}$ & 1,03 & 0,50 & 0,03 & 0,15 & 0,014 & 0,003 & 0,002 \\
\hline C & 2,04 & 0,50 & 0,02 & 0,15 & 0,015 & 0,003 & 0,004 \\
\hline D & 5,31 & 0,53 & 0,02 & 0,16 & 0,014 & 0,003 & 0,003 \\
\hline E & 9,02 & 0,48 & 0,2 & 0,15 & 0,017 & 0,003 & 0,004 \\
\hline
\end{tabular}

\section{B. Larutan Uji}

Larutan Uji dibuat dari kristal garam Lithium Bromida berwarna putih, $\mathrm{LiBr}$ (Mr=86,85 2.g/mol) dan Kristal Litium Hidroksida padat berwarna putih, $\mathrm{LiOH}$ $(\mathrm{Mr}=23,95 \mathrm{~g} / \mathrm{mol})$, kedua bahan tersebut dengan meßk Kgn A, Damstadt, Jerman.

\subsection{Preparasi Benda Uji dan Larutan Uji 4.}

Preparasi benda uji diawali dengan pemotongan pelat untuk dibentuk ukuran $5 \times 5 \times 50 \mathrm{~mm}$.
Pengamplasan dengan kertas amplas $\mathrm{SiC}$ dari ukuran 80,200,400, 600 dan 800 \# yang disertai pendingin air mengalir.

Benda uji dicuci dengan air sabun dibilas dengan air bersih dan dibilas dengan alohol dengan bantuan alat ultrasonik.

Salah satu ujung benda uji disolder/disambung dengan kabel listrik dan ditutup dengan silika gel.

Benda uji di simpan dalam desikator selama minimal 2 jam dan selanjutnya siap digunakan. 


\section{A. Preparasi Larutan Uji}

Larutan uji dibuat dengan cara mencampurkan kristal $60 \%$ berat $\mathrm{LiBr}$ dengan kristal $0,2 \%$ berat $\mathrm{LiOH}$.

Campuran kristal garam di atas dilarutkan dalam air sehingga tercapai komposisi yang tepat.

Larutan uji sebanyak $1000 \mathrm{~mL}$ dituangkan dalam sel percobaan bervolume $2000 \mathrm{~mL}$ dan ditiup gas Nitrogen selama 1 jam yang selanjutnya dipanaskan hingga mendidih $(154 \pm 2)^{\circ} \mathrm{C}$.

\subsection{Uji Asam Basa Larutan Uji}

Uji asam basa larutan uji untuk mengukur harga $\mathrm{pH}$ larutan uji $60 \% \mathrm{LiBr}+$ $0,2 \% \mathrm{LiOH}$ digunakan alat digital $\mathrm{pH}$ meter dengan kemampuan maksimum pada suhu $80^{\circ} \mathrm{C}$.

\subsection{Uji Potensial Korosi Alami}

1) Larutan uji yang siap digunakan, posisi peniupan gas Nitrogen dipindah dari bawah keatas larutan uji. Hal ini dilakukan untuk mencegah udara dari atmosfer masuk ke dalam sel percobaan.

2) Kabel benda uji dan kabel elektroda pembanding dari kalomel jenuh (SCE) dihubungkan dengan alat multitester.

3) Benda uji siap dimasukkan larutan uji dan diukur potensial korosi alaminya.

\subsection{Uji Pengaruh Udara Atmosfer Terhadap Potensial Korosi Alami}

1) Benda uji yang masih dalam larutan uji pada suhu didih $(154 \pm 2){ }^{\circ} \mathrm{C}$ dan bebas udara atmosfer, didinginkan hingga suhu ruang $(27 \pm 1)^{\circ} \mathrm{C}$.

2) Suhu larutan uji dinaikkan dari suhu ruang dengan kecepatan $10^{\circ} \mathrm{C} / 5$ menit dan diukur potensial korosi alaminya.

3) Ketika suhu larutan uji mencapai suhu didih, suhu ditahan selama 1 jam untuk mencapai kestabilan dan selanjutnya diukur potensial korosi alaminya.

4) Selanjutnya larutan uji pada suhu didih ditiup udara atmosfer sambil suhu larutan diturunkan dengan kecepatan $10^{\circ} \mathrm{C} / 10$ menit. Tiap tahap penurunan suhu ditahan selama 20 menit dan diukur potensial korosi alaminya.

\subsection{Uji Laju Korosi}

Banyak metode pengukuran laju korosi logam di lingkungan larutan berair yang diantaranya:

1. Pengurangan atau penambahan berat benda uji per satuan waktu per satuan luas.

2. Metode pembentukan gas hydrogen,

3. Metode ekstrapolasi Tafel.

Pada penelitian disini digunakan metode pengurangan berat per satuan luas per satuan waktu.

Larutan uji ( $60 \% \mathrm{LiBr}+0,2 \% \mathrm{LiOH})$ dikondisikan mendekati suhu didih (150 \pm 2$)$ ${ }^{\circ} \mathrm{C}$ dan adanya pengaruh udara atmosfer.

Waktu engujian terdiri dari 4 kali pengukuran, yaitu : 100 jam, 200 jam, 300 jam dan 400 jam

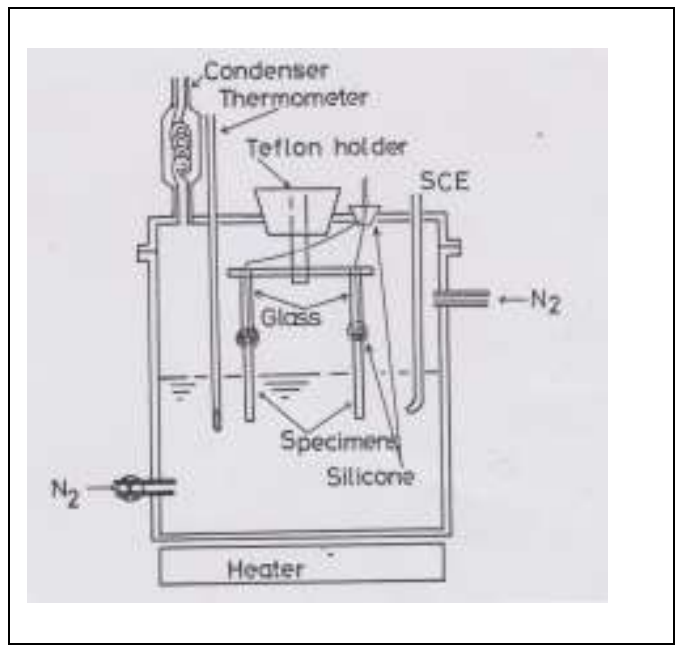

Gambar 3 : Skema sel percobaan

Skema sel percobaan yang digunakan pada penelitian ini, dapat dilihat pada gambar 3.

\section{HASIL DAN PEMBAHASAN}

\subsection{Hasil Uji Asam Basa Larutan Uji}

Berdasarkan pengukuran harga $\mathrm{pH}$ larutan uji $60 \% \mathrm{LiBr}+0,2 \% \mathrm{LiOH}$ pada suhu $80^{\circ} \mathrm{C}$, hasilnya ditunjukkan pada gambar-4. Dari Gambar-4, dapat dipelajari bahwa harga $\mathrm{pH}$ larutan uji tersebut cukup sulit untuk mencapai kestabilan. Hal ini disebabkan terlalu tinggi konsentrasi larutan garam Lithium Bromida pada suhu yang relatif tinggi yaitu $80^{\circ} \mathrm{C}$. 
Pada kondisi operasi di lapangan yang membutuhkan waktu di atas 10 jam, maka harga $\mathrm{pH}$ yang dicapai di atas angka 6 .

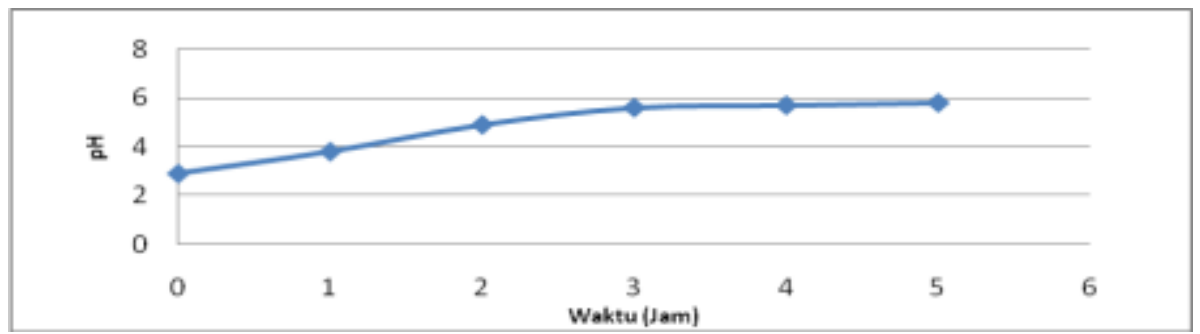

Gambar 4 : pH larutan uji $60 \% \mathrm{LiBr}+0,2 \% \mathrm{LiOH}$ pada suhu $80^{\circ} \mathrm{C}$

\subsection{Pengamatan visual hasil percoabaan pada benda uji}

Berdasarkan pengamatan visual terhadap permukaan benda uji yang telah diekpos dalam larutan uji $60 \% \mathrm{LiBr}+0,2 \%$ $\mathrm{LiOH}$ pada suhu didih $(154 \pm 2)^{\circ} \mathrm{C}$, menunjukkan adanya lapisan produk korosi yang berwarna kehitaman yang mengindikasikan adanya senyawa $\mathrm{Fe}_{3} \mathrm{O}_{4}$ "anhydroxide" yaitu senyawa magnetik. Demikian juga, larutan uji yang telah digunakan menunjukkan warna kehitaman.
Reaksi kimia yang terjadi dapat ditulis:

$$
\begin{aligned}
& 3 \mathrm{Fe}+4 \mathrm{H}_{2} \mathrm{O} \\
& \mathrm{Fe}_{3} \mathrm{O}_{4}+8 \mathrm{H}^{+}+8 \mathrm{e}^{-} \\
& \mathrm{E}_{0}=-0,085-0,0591 \mathrm{pH} \\
& 2 \mathrm{Fe}_{2}^{+}+2 \mathrm{H}_{2} \mathrm{O} \rightarrow \mathrm{HFeO}_{2}^{-}+3 \mathrm{H}^{+} \\
& 3 \mathrm{HFeO}_{2}^{-}+\mathrm{H}^{+} \\
& \mathrm{Fe}_{3} \mathrm{O}_{4}+2 \mathrm{H}_{2} \mathrm{O}+2 \mathrm{e}^{-} \mathrm{E}_{0}=-1,819+0,0295 \mathrm{pH}- \\
& 0,0886 \quad \log \left[\mathrm{HFeO}_{2}^{-}\right]
\end{aligned}
$$

\subsection{Hasil uji lajukorosi}

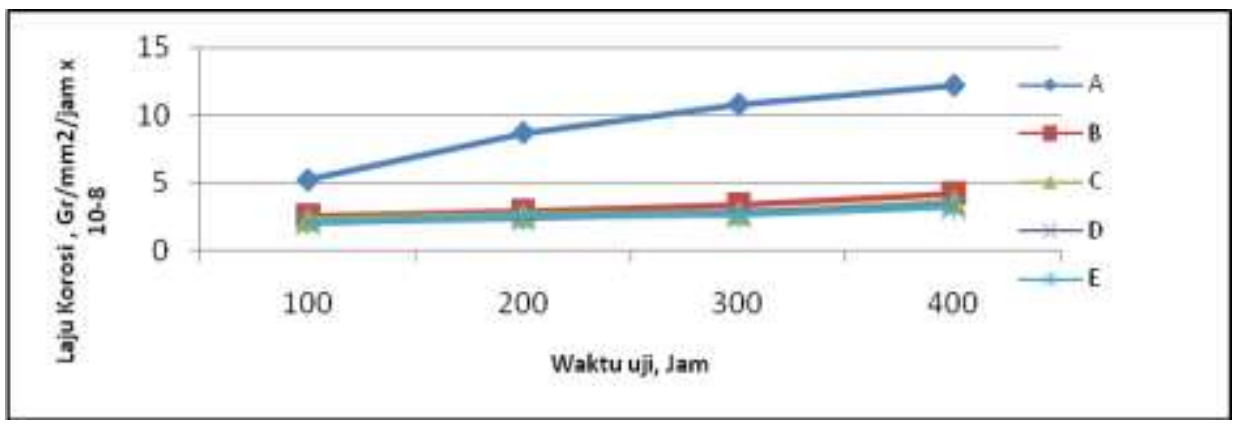

Gambar 5 : Grafik hubungan waktu ekspos terhadap laju korosi

Berdasar perhitungan laju korosi rata-rata, hasilnya ditunjukkan pada Gambar-5. Pada Gambar-5, menunjukkan bahwa laju korosi baja $A$ yang tidak mengandung unsur krom, nilainya sangat tinggi yaitu di atas $12,2\left(\mathrm{Gr} / \mathrm{mm}^{2} / \mathrm{jam} \times 10^{-8}\right)$. Di lain pihak, dengan adanya penambahan $1,03 \% \mathrm{Cr}$ laju korosi langsung tertekan hingga nilai disekitar 4,2 $\left(\mathrm{Gr} / \mathrm{mm}^{2} / \mathrm{jam} \times 10^{-8}\right)$. Dari ke-5 baja paduan tersebut nilai laju korosi terendah ada pada paduan $9,02 \% \mathrm{Cr}$ dengan nilai $3,4\left(\mathrm{Gr} / \mathrm{mm}^{2} /\right.$ jam $\left.\times 10^{-8}\right)$.
Berdasar uraian di atas, baja paduan rendah dengan unsur pemadu dari krom mempunyai peran penting untuk menurunkan laju korosi.

\subsection{Hasil Uji Potensial Korosi Alami Pada Waktu Ekspos 50 jam}

Berdasar pengukuran potensial korosi alami setelah waktu ekspos 50 jam pada suhu didih $(154 \pm 2)^{\circ} \mathrm{C}$ dan dengan penurunan suhu hingga $30^{\circ} \mathrm{C}$ hasilnya ditunjukkan pada Gambar- 6 . 


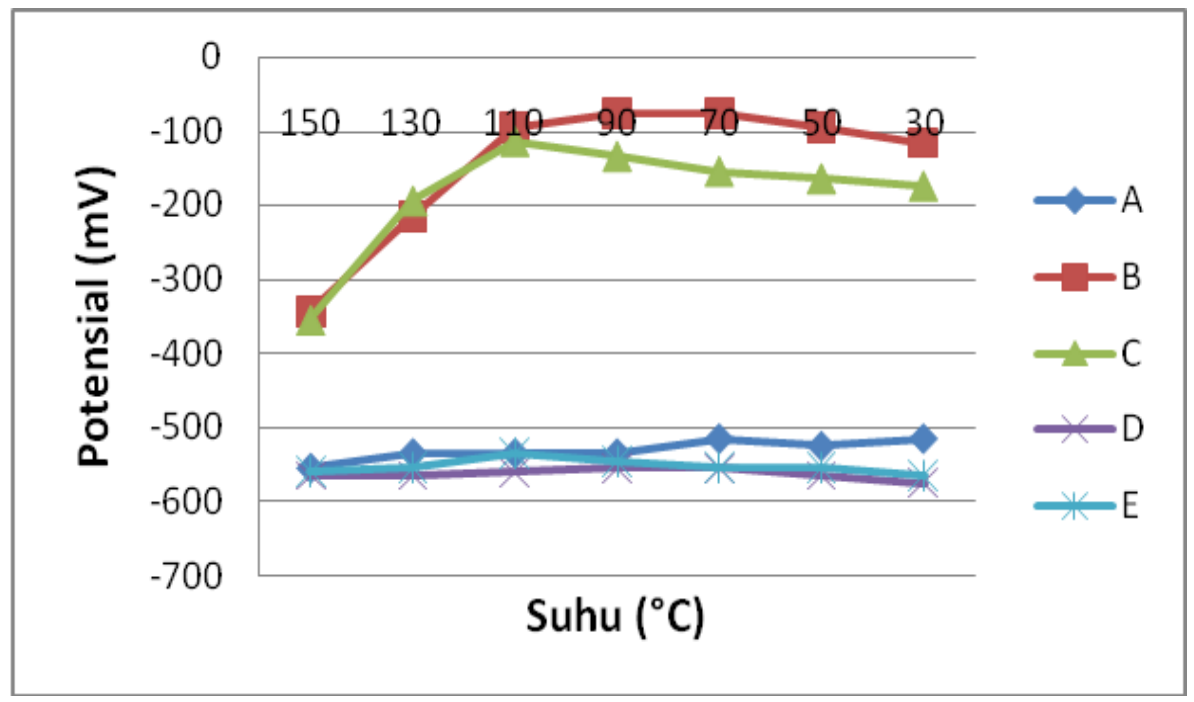

Gambar 6: Pengaruh lama injeksi udara dan suhu terhadap potensial korosi dengan waktu ekspos 50 jam

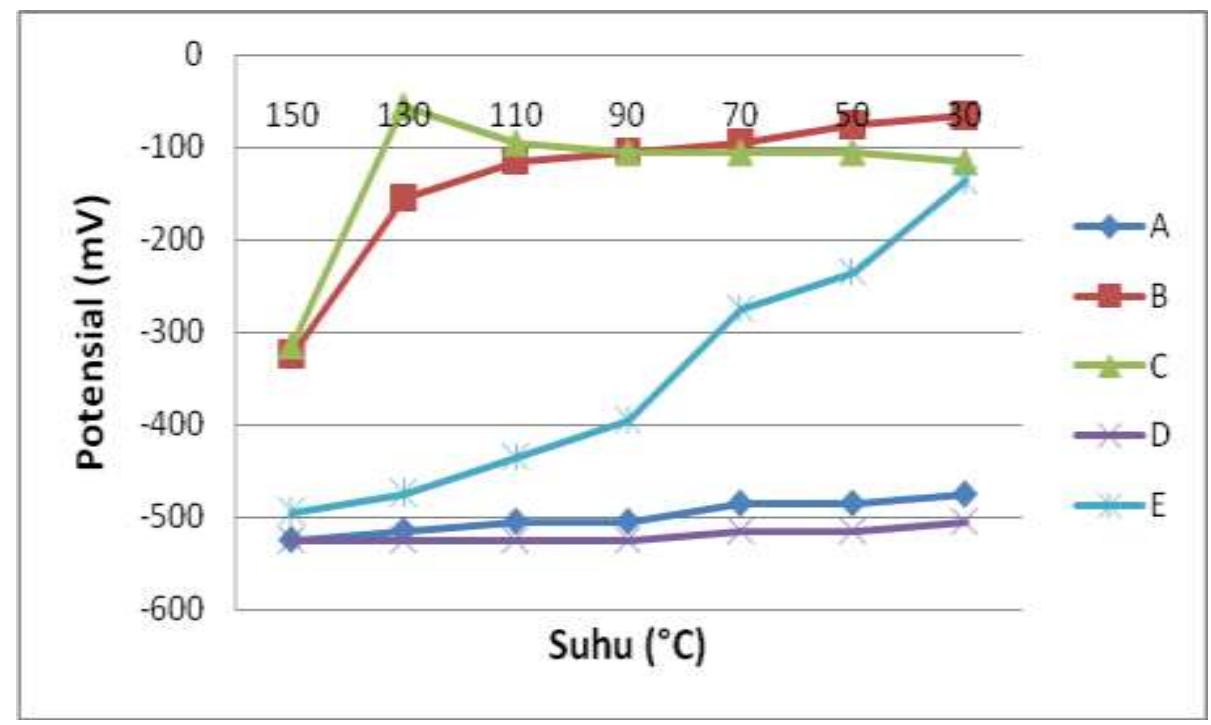

Gambar 7 : Pengaruh lama injeksi udara dan suhu terhadap potensial korosi dengan waktu ekspos 110 jam

Berdasarkan pengukuran harga potensial korosi alami pada 5 jenis baja paduan rendah dalam $60 \% \mathrm{LiBr}+0,2 \%$ $\mathrm{LiOH}$ yang diekspos selama 110 jam pada suhu didih dengan ekses udara atmosfer, hasilnya dapat dilihat pada Gambar-7.

Pada Gambar -7, dapat dipelajari hubungan harga potensial korosi alami pada penurunan suhu larutan uji dari $150^{\circ} \mathrm{C}$ ke $30^{\circ} \mathrm{C}$.

Berdasarkan Gambar -7, dapat diketahui bahwa paduan $1 \% \mathrm{Cr}$ dan $2 \% \mathrm{Cr}$ dalam logam menunjukkan adanya peningkatan harga potensial korosi alami dan mencapai angka tertinggi pada suhu $30^{\circ} \mathrm{C}$. Di pihak lain, untuk paduan $0 \% \mathrm{Cr}, 5 \% \mathrm{Cr}$ dan $9 \%$ $\mathrm{Cr}$ dalam logam pada penurunan suhu larutan uji tidak menunjukkan perubahan harga potensial korosi alaminya. $2 \% \mathrm{Cr}$ dalam logam menunjukkan adanya peningkatan harga potensial korosi alami dan mencapai angka -120 ( $m V$ vs SCE) Secara keseluruhan dari 5 jenis benda uji yang digunakan bilamana harga potensial korosinya diplot pada diagram Pourbaix 
(Gambar 8-a), baik pada ekspos dengan udara atmosfer 50 jam maupun 110 jam

(Gambar 8-b) menunjukkan dalam kondisterkorosi.

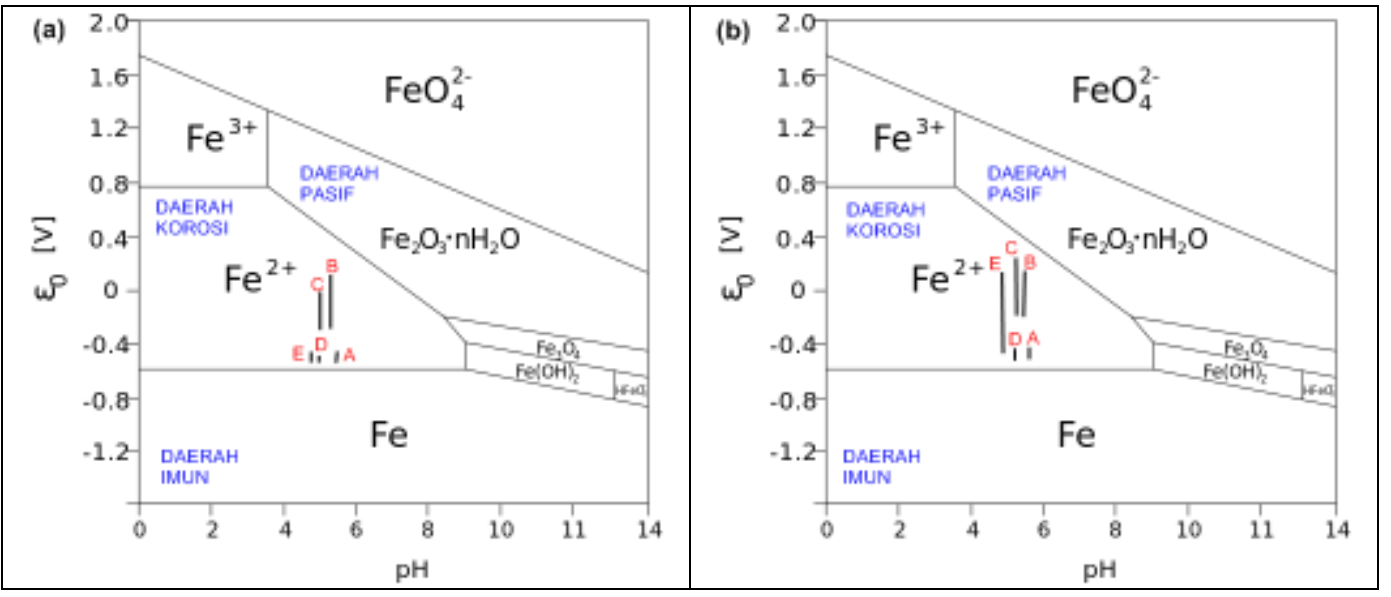

Gambar 8 : Plot data percobaan ke Diagram Pourbaix Fe-H2O (a) ekspos udara atmosfer 50 jam, (b) ekspos udara atmosfer 110 jam

\section{KESIMPULAN}

Berdasarkan penelitian dan pembahasan tentang karakteristik 5 jenis baja paduan rendah dalam media $60 \%$ $\mathrm{LiBr}+0,2 \% \mathrm{LiOH}$ pada ekspos udara atmosfer selama 50 jam dan 110 jam. Hasilnya dapat disimpulkan bahwa harga $\mathrm{pH}$ larutan uji, perlu waktu minimal 6 jam untuk mencapai kestabilannya yaitu mencapai angka di atas 6, dan Laju korosi baja paduan rendah dalam media $60 \%$ $\mathrm{LiBr}+0,2 \% \mathrm{LiOH}$ pada suhu didih, sangat tergantung pada kadar kandungan unsure krom serta pada penambahan unsur krom dalam baja paduan rendah dengan unsure mangan $0,5 \%$ berat yang diekspos dalam larutan uji, tidak menunjukkan adanya konsistensi harga potensial korosi alaminya, tetapi secara umum berada dalam keadaaan terkorosi.

\section{DAFTAR PUSTAKA}

1. Baboian ,R.," Electrochemical Techniques, National Association of Corrosion Engineers,2011

2. Fallston Maryland and Marcel Deckker, "Corrosion Engineering Handbook", New York, 2000.

3. Fontana M.G. and Grene N.D., "Corrosion Engineering", 2nd Edition, Tokyo, 2009.
4. Harsisto, "Prediksi Korosi Lokal pada Steinless Steel 304 dan 316 di lingkungan Air Laut Sintetis", Metalurgi, Volume 14 No 1, Juni 2010.

5. It. Uligh, "Corrosion and Corrosion Control", 3rd John Willey and Sons, New York, 2009.

6. John Sendriks, "Corrosion of Stainless Steels", John Willey and Sons, New York, 2010.

7. Jones, D.A.,"Principles and Prevention of Corrosion", Macmillan Publishing Company, New York. 2009,

8. L.L. Shrein PhD., 1978, "Corosion", Volume 1, Toronto, Newes-Butterworths, page 18-9 18-23. 2010.

9. Leckie H.P. and Uhliq H.H., Environmental factors Affecting the critical potential for pitting in 18-8 Stainless Steel, Journal of the Electrochemical Society, Vol. 113, No 12, Desember 2011.

10. Lima,Nascimento,Sensitization Evaluation of austenitic Stainless Steel AISI 304 L, 316L, 321 and 347, Journal of material Sciences, 40, 139. 2005, 
M.I. Mat. Konst. Vol.14 No : 2 Desember 2014 : 10 - 16 